\title{
Does hospital delay in appendectomy affect immediate surgical outcome in adults with acute appendicitis?
}

\section{Dhital SP1, Koirala U², Karki K³ , Joshi BD4, Upadhyaya AM ${ }^{5}$}

'Saroj Prasad Dhital, Senior Consultant, Department of General Surgery, Kathmandu Model Hospital; ${ }^{2}$ Udaya Koirala, Consultant, Department of General Surgery, Kathmandu Model Hospital; ${ }^{3}$ Kushal Karki, Lecturer, Department of General Surgery, KIST Medical College; ${ }^{4}$ Bijendra Dhoj Joshi, Senior Consultant, Department of General Surgery, Kathmandu Model Hospital; ${ }^{5}$ Amit Mani Upadhyaya, Consultant, Department of General Surgery, Kathmandu Model Hospital.

\begin{abstract}
Background: Emergency appendectomy is the commonest emergency surgical procedure being performed for many years. Till now, the dictum is that it should be done as soon as possible from the onset of attack.

Objectives: To evaluate immediate surgical outcome in cases undergone appendectomy after hospital delay of more than 12 hours duration compared with appendectomy done immediately within 12 hours of presentation.

Methods: This is a retrospective study of 118 patients on whom appendectomies were done between $1^{\text {st }}$ June 2008 to $31^{\text {st }}$ August 2010. These patients were divided into two groups on the basis whether the appendectomy was done $\leq 12$ hours or $>12$ hours from the time of presentation in the hospital and intergroup comparison was made regarding length of hospital stay, rate of perforation and post operative complications.

Results: A total of 118 patients were included in the study. Out of which $71(60.2 \%)$ were male and $47(39.8 \%)$ were female. Mean age of patients was $30.97 \pm 12$ years. Mean duration of hospital stay was $4.35 \pm 1.75$ days. In comparison of two groups of $\leq 12$ hours or $>12$ hours from the time of presentation in the hospital, there were no statistically significant difference in length of hospital stay ( 4.29 vs 4.4 days, $p=0.7)$, rate of perforation of appendix $(9.25 \%$ vs $10.93 \%, p=0.3)$ and post-operative wound infection ( $16.66 \%$ vs $17.18 \%, p=0.9)$.

Conclusion: Delaying an appendectomy for a valid reason can be considered. Prospective trials are required to establish findings of this study.
\end{abstract}

Key words: Appendectomy, Appendicitis, Delay, Post-operative complication.

\section{INTRODUCTION}

\begin{abstract}
A ppendectomy in acute appendicitis is the most common emergency procedure performed by a general surgeon'. The life-time risk of acute appendicitis is around $7 \%{ }^{2}$. Although the exact mechanism leading to this condition is still obscure, it is likely that luminal obstruction by external (lymphoid hyperplasia) or internal (inspissated fecal material, appendicoliths) compression plays a key pathogenic role $\mathrm{e}^{3,4,5}$. The traditional management for acute appendicitis had been an appendectomy as early as possible.
\end{abstract}

The basis of concept for emergency appendectomy at the earliest has been an increase in morbidity and

\section{Address for correspondence}

Dr. Saroj Prasad Dhital

Senior Consultant

Department of General Surgery

Kathmandu Model Hospital

E-mail:drsdhital@gmail.com mortality with delay even with few hours interval. But there are reports in pediatric patients suggesting that postponing surgery with fluid and antibiotics treatment can be safely pursued ${ }^{6}$. Risk of complications in case of delay in appendectomy for few hours seems to be overhyped. Moreover, it has also been reported that appendectomy during the midnight hours, which is the usual practice in many centers, may increase the complication rather than delaying few hours ${ }^{6}$.

Hence, this study was designed to evaluate immediate surgical outcome in cases undergone appendectomy after hospital delay of more than 12 hours duration compared with appendectomy done immediately within 12 hours of presentation, irrespective of reasons of delay.

\section{METHODS}

This is a retrospective study performed in surgical department of Kathmandu Model Hospital. Medical 
records of 118 patients on whom appendectomies were done were reviewed. Study period was from $1^{\text {st }}$ June 2008 to $31^{\text {st }}$ August 2010. All patients who underwent appendectomies during the study period were included. Patients of less than 15 years of age, incidental appendectomy, appendicitis presenting as generalized peritonitis or appendicular lumps were excluded from the study.

Hospital delay in this study is defined as delay in appendectomy for more than 12 hours after presentation to the hospital irrespective of the time of onset of pain. Delay could be due to various reasons. Appendectomy listed towards the end of the operation list, patients presenting in late night hours, patients with diagnostic dilemmas needing scans for correct diagnosis and long time taken by patient and relatives to give consent for operation were some of the examples of delay after presentation in the hospital.

All the appendectomies performed during the study period were divided into two groups on the basis if appendectomy was done $\leq 12$ hours of presentation to hospital or $>12$ hours and comparison was made in between these two groups. All the data were analyzed by using Statistical Package for Social Sciences (SPSS) version 17. Comparisons between proportions were carried out using the 2 test and student t test, and $P$ value less than 0.05 was considered statistically significant.

\section{RESULTS}

There was a total of 170 patients during the study period. Fifty two patients were excluded because of various reasons (Ten patients because of age less than 15 years, 12 patients had appendicular lump, 19 patients had appendicular perforation with peritonitis and 11 patients had undergone elective appendectomy). Hence, 118 patients were included in this study. There were 71 male and 47 female. Average age was 30.97 (age range, 15-68 years). There were 54 patients in $\leq 12$ hours groups and 64 in $>12$ hours groups. The mean \pm standard deviation time between presenting to emergency and surgery was $15.20 \pm 8.34$ hours and time to presentation to hospital was $15.66 \pm 13.59$ hours. Both groups were comparable with respect to age, sex and WBC count. There were no statistically significant differences between the two groups in the length of stay $(P=0.7)$, complications as perforation $(P=0.3)$, wound infection $(P=0.9)$ or fever $(P=0.5)$

\section{Table 1: Demographic data of study population}

\begin{tabular}{lc}
\hline Characteristics & 118 \\
\hline Total number of patients & $71: 47$ \\
\hline Male: female & $30.97 \pm 12.47$ \\
\hline Mean age in Years \pm SD & 54 \\
\hline Number of patients in $\leq 12$ hour group & 64 \\
\hline Number of patients in > 12 hour group & $15.20 \pm 8.34$ \\
\hline Mean Time of Surgery after presentation to hospital \pm SD (in hours) & $15.66 \pm 13.59$ \\
\hline Mean Time of presentation to Hospital from onset of pain \pm SD (in hours) & \\
\hline & \\
\hline Table 2: Post-operative complications of appendectomy & $20(16.94 \%)$ \\
\hline Complications (n=118) & $20(16.94 \%)$ \\
\hline Wound infection (in percentage) & 5 (4.23\%) \\
\hline Fever (in percentage) & $3(2.54 \%)$ \\
\hline Diarrhea (in percentage) & $1(0.84 \%)$ \\
\hline UTI (in percentage) & \\
\hline Wound hematoma (in percentage) & \\
\hline
\end{tabular}


Table 3: Comparison in age, sex, WBC count and mean time of surgery

\begin{tabular}{|c|c|c|c|}
\hline Characteristic & $\leq 12 \mathrm{hrs}(\mathrm{n}=54)$ & $>12 \mathrm{hrs}(\mathrm{n}=64)$ & P Value \\
\hline Mean age in years $\pm S D$ & $31.09 \pm 12.05$ & $30.87 \pm 12.91$ & $0.92 \dagger$ \\
\hline \multicolumn{4}{|l|}{ Gender } \\
\hline Male & 34 & 37 & \multirow{2}{*}{$0.5 \ddagger$} \\
\hline Female & 20 & 27 & \\
\hline $\mathrm{WBC}$ count, mean $\pm \mathrm{SD} / \mu \mathrm{L}$ & $14.80 \pm 3.9$ & $16.24 \pm .25$ & $0.7 \neq$ \\
\hline Mean time of surgery after presentation to the hospital \pm SD (in hours) & $5.30 \pm 2.10$ & $18.20 \pm 4.50$ & $0.04+$ \\
\hline
\end{tabular}

† Student's t test; $\neq \chi 2$ test

Table 4: Comparisons in primary outcome

\begin{tabular}{lccc}
\hline Characteristic & $\leq \mathbf{1 2 h r s}(\mathbf{n = 5 4 )}$ & $\mathbf{> 1 2 h r s}(\mathbf{n}=\mathbf{6 4})$ & P Value \\
\hline Length of stay (in days) & $4.29 \pm 1.44$ & $4.40 \pm 1.98$ & $0.7 \dagger$ \\
Number of perforation (in percentage) & $5(9.25 \%)$ & $7(10.93 \%)$ & $0.3 \neq$ \\
Post-op complication & & & \\
Wound Infection (in percentage) & $9(16.66 \%)$ & $11(17.18 \%)$ & $0.9 \neq$ \\
Fever (in percentage) & $12(22.22 \%)$ & $17(26.56 \%)$ & $0.5 \neq$ \\
\hline
\end{tabular}

† Student's t test; $\neq \chi 2$ test

\section{DISCUSSION}

Acute appendicitis is the most common operation done by general surgeons. It is typically done within few hours of diagnosis to prevent complications of gangrene and perforation ${ }^{4}$. With the advent of effective and multiple antibiotics and various modalities in the diagnosis of appendicitis; approach towards its management is changing.

In our study, both groups have similar outcomes though there was significant difference in time of surgery after presentation to the hospital. Hospital stay is almost same in both the groups ( 4.29 days in $\leq 12$ hours group vs 4.40 days in $>12$ hours group). More than $>12$ hours group has slightly higher appendicular perforation, postoperative fever and wound infection rate but they are statistically insignificant. This underlines the fact that delay in few hours for some valid reasons do not increase the morbidity in the patients with acute appendicitis. This finding is consistent with the findings stated by Ditillo et al which states treatment of acute appendicitis with early administration of antibiotics, fluid hydration followed by appendectomy in day hours does not increase the rate of complication, does not significantly increase length of stay or rate of advanced appendectomy ${ }^{7}$. So, there are places for discussion regarding if there should be a rush for appendectomy. Some studies suggest that the rate of perforation is due to delay in patient presentation rather than due to delay in treatment ${ }^{8}$. Hansson et al found that antibiotic treatment appears to be a safe first line therapy in unselected patient with acute appendicitis ${ }^{9}$.
Similar conclusion has been drawn in case of children with appendicitis. Surana et al found that effects of delaying appendectomies by 6 to 24 hours in children showed no significant increase in rate of perforation, operation time or complication when compared with children who underwent appendectomy within 6 hours $^{6}$.

From surgeons point of view, midnight and off hour surgeries are considered detrimental for patient outcome which is understandable and this fact should be a matter of discussion even in our scenario. Studies have shown the negative effects of sleep deprivation on clinical performance, mood and cognitive abilities ${ }^{5}$. Surgical procedures have always been a stressful situation for both the patient and patient's relatives. So this approach of delaying appendectomy to a convenient time for all concerned will always decrease the unwanted anxiety, burden and rush on behalf of surgical team and patient party.

This study is not devoid of limitations. As this study is retrospective in nature, biasness could not be ruled out completely. As the reason for delay is not stated clearly in the patient notes, we cannot certainly tell whether the delays were avoidable or not. Since time from the onset of pain was not considered for the analysis, this could be one of the confounding factor which could not be eliminated. 


\section{CONCLUSION}

Delaying surgery for a few hours for acute appendicitis for a valid reason does not significantly increase the rate of perforation, post-operative complications and length of hospital stay in adult patients. As these conclusions are derived from retrospective data, a prospective study is required to establish their validity.

\section{REFERENCES}

1. Pittman-Waller VA, Myers JG, Stewart RM. Appendicitis: Why so complicated? Analysis of 5755 consecutive appendectomies. Am Surg. 2000;66(6):548-54.

2. Ma KW, Chia NH. If not appendicitis, then what else can it be? A retrospective review of 1492 appendectomies. Hong Kong Med J. 2010;16(1):12-7.

3. Townsend CM, Beauchamp DR, Evers BM, Mattos KL. Sabiston Text book of Surgery. 18th ed. Philadelphia : Saunders; 2007.

4. Eldar S, Nash E, Sabo E. Delay of surgery in acute appendicitis. Am J Surg. 1997;173(3):194-8.

5. Wesnes KA, Walker MB, Walker LG. Cognitive performance and mood after a weekend on call in a surgical unit. Br J Surg. 1997;84(4):493-5.
6. Yardeni D, Hirschl RB, Drongowski RA, Teitelbaum DH, Geiger JD, Coran AG. Delayed versus immediate surgery in acute appendicitis: do we need to operate in the middle of the night? J Pediatr Surg. 2004;39(3):464-9.

7. Ditillo MF, Dziura JD, Rabinovici R. Is it safe to delay appendectomy in adults with acute appendicitis? Ann Surg. 2006;244(5):656-60.

8. Temple CL, Huchcroft SA, Temple WJ. The natural history of appendicitis in adults: a prospective study. Ann Surg. 1995;221(3):278-81.

9. Hansson J, Körner U, Khorram-Manesh A, Solberg A, Lundholm K. Randomized clinical trial of antibiotic therapy versus appendicectomy as primary treatment of acute appendicitis in unselected patients. Br J Surg. 2009 ;96(5):473-81. 